\title{
TEORIA CRÍTICA E EDUCAÇÃO FÍSICA: APROXIMAÇÕES A PARTIR DA ABORDAGEM CRITICO-EMANCIPATÓRIA E DIDÁTICA COMUNICATIVA
}

\author{
Cícera Andréia de SOUZA ${ }^{1}$ \\ Carmen Lúcia da Silva MARQUES ${ }^{2}$ \\ Cassiano TELLES ${ }^{3}$
}

RESUMO: Este artigo trata-se de um esforço para sintetizar as principais características da teoria social, denominada como Teoria Crítica, abordagem teórica conhecida pela crítica a Teoria Tradicional, sobretudo por situar-se como postura crítica ante a sociedade capitalista no resgate do ideal de emancipação humana. Tendo como ponto de partida as sustentações teóricas que a alicerçam e como ponto de chegada, as relações entre seus pressupostos teóricos e epistemológicos, nosso propósito centra-se na possibilidade de contribuir para a compreensão da necessidade de uma relação entre teoria e prática nas práticas pedagógicas dos professores de Educação Física, a partir de sua fundamentação na Teoria Crítico Emancipatória e Didática Comunicativa (KUNZ, 1994), que apresenta como elemento teórico fundante a Teoria Crítica da Escola de Frankfurt.

PALAVRAS-CHAVE: Teoria crítica. Educação física. Abordagem críticoemancipatória e didática comunicativa.

\section{INTRODUÇÃO}

Nem tudo o que escrevo resulta numa realização, resulta mais numa tentativa.
O que também é um prazer.
Pois nem tudo eu quero pegar. Ás vezes quero apenas tocar.
Depois, o que toca às vezes floresce e os outros podem pegar com as duas mãos.
Clarice Lispector (1995, p.12)

A partir do interesse e, sobretudo, da necessidade teórica de constituir aproximações entre a Teoria Critica, constituída a partir dos elementos da Escola de Frankfurt, caracterizada, segundo Slater (1976 apud FREITAG, 1988) como um grupo de intelectuais (Theodor W. Adorno, Max Horkheimer, Herbert Marcuse, entre outros, na primeira geração e Jürgen Habermas - entre outros -, na segunda) e a proposta pedagógica crítica da Educação Física $(\mathrm{EF})$ denominada Teoria Crítico Emancipatória e Didática Comunicativa; sentimo-nos impelidas a entender suas principais ideias e conceitos, compondo relações com os conhecimentos produzidos no espaço acadêmico

\footnotetext{
${ }^{1}$ IFPR - Instituto Federal do Paraná - Campus Avançado de Barracão. Curitiba - PR - Brasil. 80230-150 - cissadesouza@yahoo.com.br

${ }^{2}$ UFSM - Universidade Federal de Santa Maria - Departamento de Desportos Individuais. (in-memoriam) Santa Maria - RS - Brasil - 97105-900 - carminhahidro@yahoo.com.br

3 Doutorando em Educação. UFSM - Universidade Federal de Santa Maria - Pós-graduação em Educação. Santa Maria - RS - Brasil - 97105-900 - telleshz@yahoo.com.br
} 
de formação, como ponto de partida e a prática pedagógica do professor de EF teoricamente fundamentada -, no espaço da Escola, como ponto de chegada.

Partimos então, de aproximadamente 30 anos atrás, período em que teve início o processo de transformação da prática pedagógica da EF escolar. Transformar, renovar e questionar o que hegemonicamente apresentava-se como consolidado na área, ou seja, o ensino sustentado nos conhecimentos médicos - biológicos e na esportivização, passou a ser palavra de ordem.

Críticas sustentadas por diferentes teorias foram surgindo, com o intuito de mudar o contexto em vigência. Uma das críticas, segundo Kunz (2006), fundamentavase em modelos teóricos marxistas, que viam no incentivo ao esporte o mesmo processo de alienação ao qual o homem já se encontrava subsumido na sociedade. Outros modelos de crítica foram motivados especialmente a partir do questionamento do processo de ensino aprendizagem precoce dos esportes na escola, associado à obrigatoriedade da EF em todos os níveis.

Dessa forma, propostas foram realizadas com o objetivo de encontrar um caminho para a prática pedagógica "ideal” da EF o que gera até hoje muitas discussões que giram em torno, principalmente da especificidade e identidade da área.

Costa e Nascimento (2006), em seu estudo, destacaram a inexistência da relação entre a teoria e as práticas pedagógicas entre os professores pesquisados enfatizaram a partir disso, a necessidade de se buscar novos referenciais que possam facilitar a implantação de propostas mais adequadas à realidade educacional.

O distanciamento entre a teoria e a prática são constatados também a partir de Kunz (1995), que afirma haver um abismo entre o entendimento da teoria e o entendimento da prática, fato que estava intimamente relacionado, ao seu ver, à fragmentação dos conhecimentos da área da EF, como anatomia, fisiologia, psicologia, etc. Esse abismo parece que ainda hoje persiste.

No decorrer do texto veremos que a Teoria Crítica terá igualmente a preocupação de relacionar a teoria com a prática, o que será também um problema para a abordagem Crítico - emancipatória e Didática Comunicativa, uma vez que para a materialização desta proposta no contexto escolar, a teoria que a sustenta, necessita ser apreendida pelos envolvidos, no caso específico deste estudo, os professores ${ }^{4}$.

\footnotetext{
${ }^{4}$ Temos a consciência que para a materialização de uma proposta pedagógica no contexto escola, é necessário que o professor e os alunos envolvidos no ato educativo, apropriem-se de seus conhecimentos teóricos-práticos. Porém, este estudo tratará especificamente do papel do professor neste processo.
} 


\section{DESVELANDO A TEORIA CRÍTICA A LUZ DA ESCOLA DE FRANKFURT: PRIMEIRAS APROXIMAÇÕES}

Para obtermos sustentação ao tentar desvelarmos esta teoria começaremos relatando um breve histórico da mesma, na qual as considerações a seguir serão embasadas em Freitag (1986) procurando realizar um histórico sobre o como inicia esta Teoria.

Segundo Telles et al. (2011) o Instituto de Pesquisa Social foi oficialmente criado em 3 de fevereiro de 1923 e se caracterizou como um grupo de trabalho que realizava estudos, documentação e teorização sobre os movimentos operários na Europa naquele momento histórico. Desde o início este grupo esteve vinculado à Universidade de Frankfurt, apesar de ter autonomia financeira.

O primeiro diretor do Instituto foi Carl Grutenberg, historiador e marxólogo de Viena, que permaneceu no cargo até 1927 e de forma simbólica até 1930, quando assumiu Max Horkheimer, jovem filósofo formado em Frankfurt, que assumiu a cátedra de filosofia social. Com a nomeação de Horkheimer em 1930, o Instituto passou a assumir as feições de um verdadeiro centro de pesquisas, preocupado com uma análise crítica do capitalismo moderno que privilegiava a superestrutura. Era um intelectual marxista despreocupado com a burocracia e legitimação acadêmica. Investia a sua reflexão sobre a especificidade do capitalismo moderno nas condições histórica da Europa.

Graças á envergadura intelectual de Horkehimer e à sua excelente formação filosófica (elaborou teses de doutorado e livre docência sobre Kant e Hegel), conseguiu aglutinar em torno do Instituto, intelectuais como Pollock, Wittfogel, Eric Fromm, Gumpertz, Adorno, Marcuse e outros que passaram a contribuir com artigos e ensaios para a revista do Instituto.

Em 1933 o governo nazista decreta o fechamento do Instituto, por suas “atividades hostis ao estado", confiscando seu prédio, juntamente com 60.000 volumes de livros que constituíam o acervo de sua biblioteca.

Consideramos pertinente apresentar, conforme o propósito do presente estudo, os aspectos gerais da Teoria Crítica, em especial, o que compreende sua história, as obras principais, bem como seus autores e suas influências filosóficas. Procuramos, portanto, responder, entre outras, as seguintes questões: Por que e onde surge a Teoria Crítica? Quais as fontes teóricas que se embasaram seus estudiosos? Quais as principais 
obras que a fundamentam? Entendemos que essas questões se fazem necessárias porque ao defender e desenvolver a abordagem Crítico-Emancipatória, o professor deverá procurar responder estas questões para que realmente o seu ato educativo atinja a relação teoria e prática merecida na referida abordagem.

A Teoria Crítica surge em oposição a Teoria Tradicional. No ano 1937, Max Horkheimer publicou Teoria Tradicional e Teoria Crítica, onde realizou sérias críticas ao modo de se encarar o conhecimento, visto que essa primeira concepção (Teoria Tradicional) distinguia o conhecimento teórico (teoria) da transformação histórica (prática). Com isso, marca o início da Teoria Crítica da Sociedade em que é relevante destacar a influência da Escola de Frankfurt localizada na Alemanha.

A Escola de Frankfurt associada ao Instituto de Pesquisa Social da Universidade de Frankfurt surgiu através da inspiração marxista de intelectuais como o próprio Max Horkheimer, Theodor Adorno, Herbert Marcuse e Erich Fromm, tendo como um dos principais descendentes o filósofo e sociólogo alemão Jürgen Habermas. Estes estudiosos chegaram a Teoria Crítica, a partir do entendimento de que a Teoria Marxista era insuficiente para a explicação do desenvolvimento capitalista das sociedades.

O termo Escola de Frankfurt ou a concepção de uma "teoria crítica" sugerem uma unidade temática e um consenso epistemológico teórico e político que raras vezes existiu entre os representantes da Escola. $\mathrm{O}$ que caracteriza a sua atuação conjunta é a sua capacidade intelectual e crítica, sua reflexão dialética, sua competência dialógica ou aquilo que Habermas viria a chamar de "discurso", ou seja, o questionamento radical dos pressupostos de cada posição teorizada e adotada. (FREITAG, 1994 p.33-34).

Com o objetivo de melhorar a explicação dos fenômenos sociais, logo, realizadas pelo marxismo buscaram diversas fontes como Immanuel Kant, Friedrich Hegel, Sigmund Freud, Georg Lukács, Max Weber, entre outras, indo assim, os pressupostos teóricos da Teoria Crítica, muito além da explicação da organização da sociedade trabalhadora industrial, estendendo-se por áreas como a antropologia, direito, filosofia, comunicação social, sociologia, psicologia, etc. É dessa forma, que a Teoria Crítica tem como questão central o desenvolvimento de estudos críticos dos fenômenos sociais, principalmente sobre a ciência e sobre a cultura.

A crítica sobre a ciência endereçada a Teoria Tradicional realizada principalmente pelo estudo de Horkheimer (1968), conforme referido anteriormente pretende esclarecer que o homem é produtor de todas as formas históricas de vida e que 
a ciência ao utilizar situações efetivas, não pode considerar estas apenas como coisas dadas, a mercê de leis de probabilidade, mas também como situações que sofrem interferências do homem. Nessa obra, Horkheimer mostra-se ainda bastante preso ao marxismo conforme Alves-Mazotti (2002, p.116):

Para os frankfurtianos, o valor de uma teoria depende de sua relação com a práxis. Isto significa que, para ser relevante, uma teoria social tem de estar relacionada às questões nas quais, num dado momento histórico, as forças sociais mais progressistas estejam engajadas [...]

Freitag (1994, p.35), destaca a cega objetividade da ciência evidenciada pela Teoria Crítica: “A razão que hoje se manifesta na ciência e na técnica é uma razão instrumental, representativa." A primazia da técnica dada pela ciência é posta em evidência também na Dialética do Esclarecimento publicada pela primeira vez em 1947 por Adorno e Horkheimer (1985, p.18): “A técnica é a essência desse saber, que não visa conceitos e imagens, nem o prazer do discernimento, mas o método, a utilização do trabalho de outros, o capital."

Para Adorno e Horkheimer a ciência tradicional não busca a verdade, ou o "Aufklaerung" (esclarecimento), mas sim tem como função auxiliar, através de métodos, na vida dos seres humanos. Entendem que a ciência precisa colaborar para o esclarecimento e emancipação do homem, no entanto Almeida e Lucas (2010, p.9), explicam que o esclarecimento para estes autores não se refere somente ao acesso ao saber científico, mas também ao "[...] possibilitar sobre este conhecimento objetivo a crítica, negada pela ciência natural, do conteúdo oculto nesta forma de conhecer que coloca o seu controle, supremacia em questionamento."

O esclarecimento é um conceito bastante comum entre os estudiosos da Teoria Crítica. Em Dialética do Esclarecimento, o tradutor Guido Antônio de Almeida explica porque não utiliza a expressão iluminismo ou ilustração já que são palavras mais usuais para designar o que se refere à Filosofia das Luzes. Diz que a palavra esclarecimento é mais fiel àquilo que Adorno e Horkheimer quiseram representar, e que apesar de ser uma expressão mais familiar na língua alemã, encontra o mesmo significado na língua portuguesa, segundo ele:

Em Adorno e Horkheimer, o termo é usado para designar o processo de "desencantamento do mundo", pelo qual as pessoas se libertam do medo de uma natureza desconhecida, à qual atribuem poderes ocultos 
para explicar seu desamparo em face dela. Por isso mesmo, o esclarecimento de que falam não é, como o iluminismo, ou a ilustração, um movimento filosófico ou uma época histórica determinados, mas o processo pelo qual, ao longo da história, os homens se libertam das potências míticas da natureza, ou seja, o processo de racionalização que prossegue na filosofia e na ciência. (ADORNO; HORKHEIMER, 1985, p.7-8).

Após essa breve sinalização de como ocorre o desenvolvimento da Teoria Crítica e destacado os seus estudiosos e suas influências teóricas, ainda que de forma concisa, importa agora nos determos em seus princípios fundamentais, ou seja, explicitar os conceitos essenciais para o seu entendimento, e no que, basicamente ela difere das demais.

\section{A TEORIA CRÍTICA E SEUS PRINCÍPIOS FUNDAMENTAIS}

Devido à oposição a Teoria Tradicional, a questão sobre teoria e prática tornouse central para a Teoria Crítica, sendo assim, podemos considerar como um ponto importante para este estudo, compreender como essa entende a prática e a teoria e seu entendimento acerca desses dois elementos.

Na perspectiva da Teoria Critica uma teoria possui hipóteses e argumentos que visam explicar fenômenos diversos. E mais:

Uma teoria, para ser considerada científica, deve ainda, ser capaz de
produzir prognósticos, ou seja, de dizer o que está para acontecer se as
condições precedentes forem satisfeitas. Uma teoria é corroborada ou
refutada quando os prognósticos baseados nas suas hipóteses se
confirmam ou não. (VIEIRA; CALDAS, 2006, p.60).

Porém, conforme descrito anteriormente, uma das preocupações da Teoria Crítica reside no esclarecimento e na emancipação do ser humano, dessa forma uma questão surge: como promover o esclarecimento sem que a teoria esteja atrelada a prática reflexiva e transformadora? Para responder a essa questão a Teoria Crítica questiona o tratamento dado pela Teoria Tradicional aos conceitos de teoria e prática, a partir do uso da categoria Crítica. "Criticar não significa abdicar de conhecer o mundo como ele é tampouco, de pensar como ele deveria ser." (VIEIRA; CALDAS, 2006, p.60).

Nesse sentido, a Teoria Crítica procura realizar seus estudos a partir de como as coisas são e de como elas deveriam ser através das possibilidades advindos da sociedade. 
A teoria crítica aponta para a prática a partir da realização desses potenciais, por meio da identificação e rompimento dos obstáculos. É a teoria no ato. O ato é aquele da realização dos potenciais do mundo, e tais potenciais são de natureza necessariamente emancipatória. (VIEIRA; CALDAS, 2006, p.60-61).

A descrição do mundo a partir do que ele é, para a Teoria Crítica é sempre incompleta, pois não abarca a possibilidade do que ele pode vir a ser.

Além da preocupação de relacionar teoria e prática, a Teoria Crítica tem como princípios fundamentais a orientação para o esclarecimento a partir do que é e do que pode vir a ser, sempre se preocupando com a criticidade em relação a tudo e sendo contrária a neutralidade e passividade positivista ${ }^{5}$.

Não há como dissociar esse o que é e o que deveria ser, ou seja, para os teóricos críticos não é possível pensar a realidade partindo apenas do que existe ou de como ela é, fazendo-se necessário refletir como essa realidade pode transformar-se, no que ela pode vir a se tornar. "[...] o "dever ser" se refere às possibilidades não realizadas pelo mundo social. Não tem caráter utópico, mas analisa o que o mundo poderia ter de melhor se suas potencialidades se realizassem.” (VIEIRA; CALDAS, 2006, p.60).

Não se trata de descrever a realidade social como algo objetivo como defendem os positivistas e até mesmo, ao que tudo indica os marxistas. Ambos, positivistas e marxistas, pretendem descrever a realidade a partir dos seus pontos de vista, os positivistas por meio da experimentação e os marxistas através das descrições sobre as relações das classes sociais e do trabalho, pressupondo que o resultado final é objetivo. Segundo Matthews (2006) o marxismo vê os seres humanos como objetos pelo fato de que sua consciência subjetiva da situação em que se encontram e a influência dessa subjetividade sobre seu comportamento são negadas ou, pelo menos, desconsideradas: supõe-se que a forma como se comportam é inteiramente determinada de fora, pela ação de forças externas sobre eles.

Para descrever, interpretar e criticar o mundo da vida cotidiana, principal preocupação da teoria crítica, a mesma utiliza-se dos pressupostos filosóficos da

${ }^{5}$ O Positivismo corresponde a Teoria Tradicional, a ideologia se fundamenta no conhecimento dos fatos por meio da experimentação. Segundo Löwy (1994) as premissas que se seguem descrevem a visão de mundo positivista: A sociedade é regida por leis naturais - invariáveis, independente da ação humana. A sociedade pode ser assimilada pela natureza (naturalismo positivista) e ser estudada pelos mesmos métodos. As ciências da sociedade, assim como as da natureza devem limitar-se à observação e à explicação causal dos fenômenos, de forma objetiva, neutra, livre de julgamentos de valor ou ideologias, descartando previamente todas as prenoções e preconceitos. 
fenomenologia. Merleau Ponty entende a fenomenologia como uma forma de subverter os pressupostos objetivistas, segundo Matthews (2006, p.165) “[...] os seres humanos são sujeitos, mas a forma específica que assume sua subjetividade é condicionada pelo fato de serem incorporados. Os seres humanos são incorporados, mas a natureza dessa corporeidade é condicionada pelo fato de serem sujeitos.”

A fenomenologia moderna teve como fundador o filósofo e matemático Edmund Husserl que produziu uma vasta obra que se destaca principalmente pela profundidade dos conceitos. Compreender a fenomenologia é certamente algo de extrema complexidade. De modo geral, podemos conceituá-la como uma maneira de descrever os fenômenos a partir da relação entre o eu e a coisa, o sujeito e o objeto. Dartigues (1992) destaca três grandes linhas na fenomenologia, a transcendental, de Husserl, a existencial, que parte de Jean-Paul Sartre e Maurice Merleau-Ponty, e a hermenêutica que tem como seus principais representantes Hans George Gadamer e Martin Heidegger.

A hermenêutica se destaca na fenomenologia e por consequência na Teoria crítica. Isso se dá, pois, para interpretar algo se precisa da linguagem. Linguagem e hermenêutica são termos vinculados. Segundo Ruedell (2008, p.223) “[...] de um lado parte-se, normalmente, de uma concepção geral de hermenêutica como a teoria da interpretação, a qual, por sua vez, é originalmente interpretação de linguagem.” E o mesmo autor continua: "De outro lado, a linguagem é geralmente vista como meio de comunicação e, inclusive, de constituição do pensamento. Para isso necessita, muitas vezes, ser interpretada, para superar mal entendidos e elucidar o próprio pensamento." De acordo com Cohen e Omery (1994, p.148):

[...] a hermenêutica como um método de pesquisa assenta-se na tese ontológica de que a experiência vivida é em si mesmo essencialmente um processo interpretativo. A tarefa fenomenológica é a autointerpretação explicitamente ontológica.

O entendimento da interação, da experiência vivida, entre as pessoas é interpretado através do uso da linguagem. Assim, segundo Coltro (2000) o método fenomenológico - hermenêutico propõe uma ampla reflexão, constante e contínua sobre a importância, validade e finalidade dos questionamentos, indagações e respostas obtidas. 
Freitag (1994) separa a Teoria Crítica em três momentos onde busca estrategicamente destacar as reflexões realizadas em determinadas épocas por seus teóricos, onde é evidenciada, principalmente no terceiro momento a importância da linguagem para o processo de emancipação humana. No primeiro momento a autora destaca o debate entre o pensamento cartesiano e o pensamento marxista através do confronto entre Descartes e Marx realizado por Horkheimer.

Em um segundo momento, Popper e Adorno debatem os fundamentos epistemológicos do positivismo e da dialética. E no terceiro momento é tematizado o conceito de razão, através do conceito de razão comunicativa ou dialógica em oposição à teoria sistêmica. A teoria da ação comunicativa proposta por Habermas irá contraporse a teoria sistêmica proposta por Luhmann que tem como uma de suas características a exclusão do diálogo e dos questionamentos, através da razão instrumental, o que vem de encontro com as ideias defendidas nos momentos anteriores da Teoria Crítica, ou seja, a validade da linguagem não é questionada indo contra as tendências emancipatórias defendidas também no primeiro e segundo momento da história da Teoria Crítica. A teoria de Habermas terá grande importância para a EF, pois servirá como principal referência da abordagem Crítico-Emancipatória.

\section{DA TEORIA CRÍTICA À ABORDAGEM CRITICO-EMANCIPATÓRIA E DIDÁTICA COMUNICATIVA - APROXIMAÇÕES NA PRÁTICA PEDAGÓGICA}

Até aqui, procuramos entender as principais características da Teoria Crítica, o seu posicionamento frente à Teoria Tradicional, as principais obras e estudiosos e seus conceitos essenciais como: teoria, prática, esclarecimento, emancipação, crítica, fenomenologia e hermenêutica.

Tendo em vista nosso propósito em firmar relações teóricas entre a Teoria Crítica e a abordagem Crítico - Emancipatória e Didática Comunicativa, com um fim na relação teoria e prática no âmbito do trabalho pedagógico no espaço escolar, partimos em busca dessa compreensão.

Para falarmos na abordagem teórica Crítico - Emancipatória e Didática Comunicativa no ensino da EF cabe salientar, sobretudo, sua origem epistemológica, que se ancora na Teoria Crítica, especificamente na Escola de Frankfurt, especialmente no que diz respeito às produções de Jürgen Habermas, em relação aos pressupostos 
relacionados à emancipação humana e à racionalidade comunicativa $^{6}$, e a Fenomenologia, no que alude ao Se - movimentar Humano ${ }^{7}$.

Essa proposta pedagógica, alicerçada em tais teorias fundantes, engendra consideráveis críticas ao esporte como conteúdo de ensino da EF. Em 1991, Kunz publicou a obra Ensino e Mudança, e em 1994, publicou Transformação didáticopedagógica do esporte, estas duas obras vieram a dar início à abordagem Crítico Emancipatória e Didática Comunicativa da EF. Para entender a relação que Kunz (1991, 1994) realizou entre a Teoria Crítica e a EF é necessário ver um pouco mais da teoria que a permeia.

Pires (2002), nos traz que o primeiro aporte teórico a ser considerado para compreender os fundamentos da concepção Crítico - Emancipatória e Didática Comunicativa é recolhido da Teoria da Ação Comunicativa de Jürgen Habermas, um dos estudiosos representantes da Teoria Crítica conforme citamos anteriormente. A teoria da ação comunicativa, segundo Pires (2002), se refere à identificação de duas esferas que compõem as sociedades contemporâneas: o sistema e o mundo vivido.

O sistema “[...] significa o campo da reprodução material ou do trabalho, representado pelas estruturas sociais ou subsistemas da economia e do estado/poder, onde predominam a racionalidade instrumental, o discurso técnico e o agir estratégico." (PIRES, 2002, p.124). Já o mundo vivido refere-se a “[...] interação simbólica através da experiência comum a todos os atores sociais, isto é, a cultura compartilhada, onde são privilegiados a razão comunicativa e o discurso normativo.” (PIRES, 2002, p.124).

Estas duas esferas se complementariam, no entanto, Pires (2002) destaca que Habermas aponta dois problemas do sistema e do mundo vivido em relação à característica da transformação da sociedade na modernidade. O primeiro deles seria...

[...] o "desengate" entre sistema e mundo vivido o que implicaria na naturalização da economia, da racionalidade técnica, dispensando, portanto, o âmbito normativo da valoração e da moral comum ao

\footnotetext{
${ }^{6}$ Os principais aspectos relacionados a esta Escola, ressalvadas as peculiaridades dos intelectuais que a compõe, situa-se na postura crítica ante a sociedade capitalista e ao pensamento moderno e no resgate do ideal de emancipação humana. Jürgen Habermas, um de seus representantes (e uma das referências da Teoria Crítico-Emancipatória e Didática Comunicativa), conforme Freitag (1988), pauta seus estudos na razão comunicativa e atribui ao agir comunicativo caráter emancipatório.

${ }^{7}$ A Teoria do Se - movimentar Humano contrapõe-se à compreensão do movimento humano como o de deslocamento de um corpo físico no espaço e no tempo - concepção fundada nas Ciências Naturais (HILDEBRANDT-STRAMANN, 2003). Além disso, compreende o movimento humano como diálogo entre homem e mundo, no qual se inter-relacionam três elementos: o sujeito que se movimenta, a situação (mundo) a que esta ação se relaciona e os sentidos e significados atribuídos a este diálogo (GORDJIN, 1970 apud KUNZ, 2004).
} 
mundo vivido." (PIRES, 2002, p.124). O segundo problema tem a ver com a "colonização" do mundo vivido por intervenção da racionalidade da técnica e do agir estratégico, típico do sistema. (PIRES, 2002, p.124).

É através destes fundamentos que a abordagem Crítico - Emancipatória e Didática Comunicativa procura diagnosticar o contexto da EF atual. Partindo do entendimento que o esporte como elemento da cultura de movimento integraria o mundo vivido, Kunz critica a "colonização" do mesmo, ou seja, a sua transformação em

mais um objeto do sistema, que acaba sendo naturalizado pela dissociação entre o mundo vivido e o sistema, que por conta disso não é questionado como deveria pela sociedade.

[...] o sentido atribuído pelo sistema ao esporte torna-se unívoco e hipostasiado, sendo gerado pela lógica da racionalidade instrumental, o que proporciona uma espécie de legitimação técnica para as consequências nefastas decorrentes desse processo, tais como a exclusão, a mercadorização e a instrumentalização, incluindo ainda o uso de expedientes escusos destinados à obtenção imediata de sucesso e lucro a qualquer custo. (PIRES, 2002, p.125-126).

A abordagem Crítico - Emancipatória e Didático Comunicativa da EF é fundamental, pois através da mediação do professor que os alunos terão a possibilidade de enxergar de maneira crítica do fenômeno do esporte. Kunz (2006) enfatiza que para o esporte ser compreendido na sua dimensão polissêmica, deve-se ir além da prática nas aulas de EF, segundo ele "[...] é da mais alta importância, sem dúvida, a competência comunicativa que lhes possibilita a comunicação, não apenas sobre o mundo dos esportes, mas para todo o seu relacionamento com o mundo social, político, econômico e cultural.” (KUNZ, 2006, p.29-30).

Fazer com que o aluno se torne emancipado, como sugere o nome da abordagem, ou ainda, esclarecido, é tido como tarefa fundamental da educação. E isso implica, segundo Kunz (2006, p.32) “[...] principalmente, num processo de esclarecimento racional e se estabelece num processo comunicativo."

A linguagem, a comunicação, como é possível perceber, tem um papel fundamental nesta concepção, descendendo da Ação Comunicativa de Habermas. Assim, a constituição do processo de ensino se dá principalmente através da categoria linguagem, subsidiando as categorias: trabalho e interação. Essas categorias, segundo 
Kunz apud Mayer (1987), formarão a mediação dos estudantes com os conteúdos e a realidade do mundo.

Para que o professor trabalhe a partir da concepção Crítico - Emancipatória e Didática Comunicativa, é preciso ir além do trabalho de treinar as técnicas e habilidades. Kunz (2006) enfatiza que para que o aluno possa compreender o esporte nos seus múltiplos sentidos e significados para nele poder agir com liberdade e autonomia, ele precisa ir além da capacidade objetiva de saber efetivamente jogar o esporte.

É necessário que o aluno estude o esporte, que desenvolva também as capacidades comunicativa e social. Desenvolver a competência comunicativa, é fundamental para o desenvolvimento da competência objetiva e da competência social, é através do diálogo que se compreenderá melhor a técnica (trabalho) a ser realizada, é que agirá de forma solidária, participativa (interação social), é por isso que a linguagem é considerada tão importante.

Dessa forma, podemos identificar o seguinte esquema:

\begin{tabular}{l} 
Trabalho: Competência Objetiva - Está relacionado ás \\
habilidades e técnicas dos esportes. \\
\hline $\begin{array}{l}\text { Interação: Competência Social }- \text { Está relacionada ao vínculo } \\
\text { entre esporte e sociedade. }\end{array}$ \\
\hline $\begin{array}{l}\text { Linguagem: Competência Comunicativa - Está relacionada aos } \\
\text { conteúdos que transcendem a simples prática do esporte, é a } \\
\text { crítica, a capacidade de julgar o fenômeno esportivo. }\end{array}$
\end{tabular}

Vê-se assim que a abordagem Crítico - Emancipatória e Didática Comunicativa da EF está intimamente relacionada à Teoria Crítica, de modo que segue o mesmo entendimento da necessidade de esclarecimento e emancipação, de crítica ao modelo tradicional, positivista, e principalmente por entender que a linguagem, a razão comunicativa é que permeia as relações humanas em busca da emancipação.

No entanto, assim como acontece em outras abordagens, que surgiram em função da necessidade de mudança no ensino da EF, a Crítico - Emancipatória e Didática Comunicativa sofre com o distanciamento, visto por grande parte dos professores da área, da teoria e da prática, exigindo de todos o desafio de buscar compreender a Teoria para que esta subsidie a prática de fato. 
PHYSICAL EDUCATION AND CRITICAL THEORY: APPROACHES FROM THE APPROACH CRITICAL-EMANCIPATORY AND TEACHING COMUNICATIVA

ABSTRACT: This article is in an effort to summarize the main features of social theory, referred to as Critical Theory, theoretical approach known by the Traditional Theory critical, especially as it is situated as a critical stance against capitalist society in the rescue of the ideal of human emancipation. Taking as a starting point supports the theoretical underpinning and as a point of arrival, the relationships between its theoretical and epistemological assumptions, our purpose focuses on the possibility of contributing to the understanding of the need for a link between theory and practice in teaching practices teachers of Physical Education, from its foundation in Critical Theory and Emancipatory Teaching Communicative (Kunz, 1994), which presents as foundational theoretical element Critical Theory of the Frankfurt School.

KEYWORDS: Critical theory. Physical education. Critical approach - emancipation and communicative teaching.

\section{REFERÊNCIAS}

ADORNO, T. W.; HORKHEIMER, M. Dialética do esclarecimento. Tradução de Guido Antônio de Almeida. Rio de Janeiro: Zahar, 1985.

ALMEIDA, A. S. de; LUCAS, B. B. A Educação Física sob nova direção de Kunz. Conexões: Revista da Faculdade de Educação Física da UNICAMP, Campinas, v.8, n.1, p.77-99, jan./abr. 2010.

ALVES-MAZOTTI, A. J. Repensando algumas questões sobre o trabalho infantojuvenil. Revista Brasileira de Educação, Rio de Janeiro, n.19, p.87-118, jan./abr. 2002.

COHEN, M. Z.; OMERY, A. Schools of phenomenology. In: MORSE, J. M. (Ed.). Critical issues inqualitative research. Thousand Oaks: Sage, 1994. p.136-156.

COLTRO, A. A. fenomenologia: um enfoque metodológico para além da modernidade. Caderno de Pesquisa em Administração, São Paulo, v.1, n.11, p.37-45, 2000.

COSTA, L. C. A. da; NASCIMENTO, J. V. do. Prática pedagógica de professores de educação física: conteúdos e abordagens pedagógicas. Revista da Educação Física/UEM, Maringá, v.17, n.2, p.161-167, 2006.

DARTIGUES, A. O que é fenomenologia? 3.ed. São Paulo: Moraes, 1992.

FREITAG, B. A teoria crítica: ontem e hoje. 5.ed. São Paulo: Brasiliense, 1994. . Escola, estado e sociedade. São Paulo: Cortez, 1988. A teoria crítica: ontem e hoje. São Paulo: Brasiliense, 1986. 
HILDEBRANDT-STRAMANN, R. Textos pedagógicos sobre o ensino da educação física. 2.ed. Ijuí: Ed. da Unijuí, 2003.

HORKHEIMER, M. Filosofia e teoria crítica. In: BENJAMIN, W. et al. Textos Escolhidos. São Paulo: Abril, 1968. p.163. (Coleção Os Pensadores).

KUNZ, E. Transformação didático-pedagógica do esporte. 7.ed. Ijuí: Ed. da Unijuí, 2006. (Coleção educação física).

Transformação didático-pedagógica do esporte. 6.ed. Ijuí: Ed. da Unijuí, 2004.

Teoria/Prática de Ensino/Pesquisa da Educação Física. Motrivivência, Florianópolis, v.7, n.8, p.46-54, dez. 1995.

Transformação didático-pedagógica do esporte. Ijuí: Ed. da Unijuí, 1994. (Coleção educação física).

. Educação Física: ensino e mudança. Ijuí: Ed. da Unijuí, 1991. (Coleção educação física).

LISPECTOR, C. A cidade sitiada. 8.ed. Rio de Janeiro: Francisco Alves, 1995.

LÖWY, M. As aventuras de Karl Marx contra o Barão de Müchhausen: marxismo e positivismo na sociologia do conhecimento. São Paulo: Cortez, 1994.

PIRES, G. de L. Educação Física e o discurso midiático: abordagem críticoemancipatória. Ijuí: Ed. da Unijuí, 2002. (Coleção educação física).

MATTHEWS, E. Compreender Merleau-Ponty. Tradução de Marcus Penchel. 2.ed. Petrópolis: Vozes, 2006. (Série Compreender).

MAYER, A.C. A importância dos 'quase-grupos' no estudo das sociedades complexas. In: FELDMAN-BIANCO, B. (Org.). Antropologia das sociedades contemporâneas. São Paulo: Global, 1987. p.127-158.

RUEDELL, A. Hermenêutica. In: GONZÁLEZ, F. J.; FENSTERSEIFER, P. E. (Org.). Dicionário crítico de educação física. 2.ed. rev. Ijuí: Ed. Unijuí, 2008. p.189-245. (Coleção educação física).

TELLES, C. et al. Teoria crítica e Educação: os pensadores frankfurtianos e suas contribuições. Revista Virtual P@ rtes, São Paulo, out. 2011. Disponível em: <http://www.partes.com.br/educacao/artigos/teoriacritica.asp >. Acesso em: 24 mar. 2016.

VIEIRA, M. M. F.; CALDAS, M. P. Teoria crítica e pós-modernismo: principais alternativas à hegemonia funcionalista. RAE, Rio de Janeiro, v.46, n.1, p.59-70, jan./mar, 2006. 